\title{
Usefulness of screening tools in the evaluation of long-term effectiveness of DREZ lesioning in the treatment of neuropathic pain after brachial plexus injury
}

\author{
Pavel Haninec ${ }^{1}$, Radek Kaiser ${ }^{1 *}$, Libor Mencl ${ }^{1}$ and Petr Waldauf ${ }^{2}$
}

\begin{abstract}
Background: Despite high success rate of DREZ lesioning in the treatment of intractable central pain, there is still a significant incidence of patients without satisfactory post-operative effect. The aim of the study was to evaluate the long-term effect of DREZ lesioning using both a subjective assessment using a visual analog scale (VAS) to quantify residual pain and an assessment using the screening tool (painDETECT Questionnaire, PD-Q).
\end{abstract}

Methods: DREZ lesioning was performed in 52 patients from a total 441 cases with brachial plexus injury (11.8\%) during a 17-year period (1995-2011). The effect of surgery was retrospectively assessed in 48 patients.

Results: A decrease in pre-operative pain by more than $75 \%$ (Group I) was achieved in $70.8 \%$ of patients and another 20.8\% reported significant improvement (Group II). The surgery was unsucessful in 8.4\% (Group III). We found a significant correlation between 'improvement' groups from both methods of assessments. Patients from Group I usually complained of residual nociceptive pain according to PD-Q, patients from Group II typically had pain of unclear origin, and all cases those in Group III suffered from neuropathic pain, Cramer's $V=.66, P<.001$. Overall, $66.7 \%$ of patients had resolved neuropathic pain, $20.8 \%$ patients had more serious complaints and may also suffer from residual neuropathic pain, while $12.5 \%$ had unresolved neuropathic pain.

Conclusion: DREZ lesioning is a safe and effective method with success rates of about 90\%. PD-Q scores correspond to subjective satisfaction with the surgery and it seems to be a suitable screening tool for finding patients with residual neuropathic pain after surgery.

Keywords: DREZ lesioning, Deafferentation pain, Screening tool, Neuropathic pain, Brachial plexus injury

\section{Background}

Pain is an early symptom in up to $70 \%$ of patients with brachial plexus injury. In up to $20 \%$ of cases severe intractable pain develops. Persistent pain with sporadic acral irritations described by patients as cutting or burning, is typical [1,2]. In $90 \%$, the pain corresponds to the avulsion of one of the lower roots. Pain does not appear at the time of injury, but typically several days after. Pathophysiology of the pain is not fully clarified, but it originates after the loss of sensory impulses from the

\footnotetext{
* Correspondence: rkaiser@hotmail.cz

${ }^{1}$ Department of Neurosurgery, Third Faculty of Medicine, Charles University, Hospital Kralovske Vinohrady, Srobarova 50100 34, Prague, Czech Republic
} Full list of author information is available at the end of the article periphery which leads to the creation of pathologic pain generator in the dorsal horn of the spinal cord, in Rexed's lamina I [3]. Irritations are treatable with standard analgesics in the early stages and often surcease with the restoration of sensory innervation of the median nerve. Although central neuropathic pain is often refractory, pharmacotherapy may give satisfactory or even good relief. Worth trying are the gabapentinoids, tricyclic antidepressants, tramadol, and for partial injuries, lamotrigine $[4,5]$. However, if pain treatment is inadequate and pain progresses it indicates that a central component is present. The only causal therapy is in these situations is DREZ (dorsal root entry zone) thermocoagulation (DREZT) $[2,3,6-10]$, which was first described by Nashold [8]. 
This method can also be used for trigeminal or postherpetic neuralgia or in pain after spinal cord trauma, but results are generally not as favorable [11].

To our knowledge, no study has evaluated residual neuropathic pain or success of DREZ-T using a screening tool. The painDETECT Questionnaire (PD-Q) was developed in Germany for use in individuals with back pain and incorporates an easy to use patient-based (selfreport) questionnaire that does not require a clinical examination [12].

The aim of this study was to evaluate the long-term effect of DREZ-T in patients treated for severe neuropathic pain that developed after brachial plexus injury. The evaluation used both a subjective assessment using a visual analog scale (VAS) to quantify residual pain and an assessment using the PD-Q score [12]. Additionally, we wanted to test the usefulness of the screening tools in evaluating residual neuropathic pain in such patients.

\section{Methods}

A total of 52 DREZ thermocoagulations have been performed, by the senior author, during the period 1995 2011 (P. H., Dept. of Neurosurgery, General Military Hospital, Prague, since 1998 present department). Surgical procedures were completed on 48 men and four women with an average age of 40 years $(S D=9.6$, range 21 - 70). Twenty-nine cases were localized on the right and 23 on the left side. Patient data are summarized in Table 1.

The study was approved by the hospital institutional review board and informed consent to participate in the study and for the publication of individual clinical details was obtained from each patient.

\section{Indication criteria}

Patients were indicated for DREZ-T after development of severe, unbearable pain in the affected extremity after all types of analgesia (including high dose of opioids, anticonvulsants and tricyclic antidepressants) had been tried and found to be inadequate. The vast majority of procedures were performed before a planned reconstruction of the brachial plexus. All patients underwent preoperative EMG examination using needle concentric electrodes and nerve conduction studies. CT myelography showed avulsion of minimally two cervical roots in all patients.

\section{Operative technique}

The procedures were performed in the semi-sitting position with the head fixed in three-point fixation after shaving the occipital area. An incision was made vertically from external occipital protuberance to the vertebra prominens. Multilevel hemilaminectomies (2-4) were performed to expose the spinal cord at the level of the nerve root avulsion. Laminectomy and durotomy were extended until finding the nearest outgoing posterior root. The lesions were made after DREZ localization (see below), using a radiofrequency electrode with a tip depth $2 \mathrm{~mm}$ under the spinal cord surface. Lesioning time was $15 \mathrm{~s}$, lesioning temperature was $75^{\circ} \mathrm{C}$; lesioning device was a Radionics RFG-3C Plus (Valleylab, Colorado, USA).

The strip electrode with two active members (each $1 \mathrm{~mm}$ in diameter, $5 \mathrm{~mm}$ distance between them) was slipped under the dura at the rostral end of exposed spinal cord. Responses were amplified at a gain setting of 100 with the high frequency filter set at $5 \mathrm{kHz}$ and the low frequency filter set at $20 \mathrm{~Hz}$. Responses were not averaged (Dantec Counterpoint 2, Minneapolis, USA). The stimulating electrode was a bipolar stimulating electrode with constant distance between tips of $1 \mathrm{~mm}$. A $200-\mu$ sec square-wave impulse and a stimulation rate of 3 stimuli per second were used.

Initially the stimulating electrode was placed over the dorsal column. The distance between stimulating and recording electrodes varied from 3 to $8 \mathrm{~cm}$. The intensity of the stimulus was gradually increased until an evoked potential with amplitude of approximately $30-50 \mathrm{uV}$ was elicited. The stimulus intensity was not changed during the rest of procedure and ranged from 0.1 to $0.9 \mathrm{~mA}$. Using an operating microscope, the neurosurgeon gradually stimulated dorsolateral surface of spinal cord at a constant distance from the registration electrode, in approximately $2 \mathrm{~mm}$ steps. Sites where the stimulation electrode failed to evoke a response were considered DREZ and a thermocoagulation lesion was made at that site. The stimulating technique was repeated along the long axis of the spinal cord at $1 \mathrm{~cm}$ intervals. Our operative technique was previously published [10].

\section{Postoperative examination}

All patients were hospitalized for one week. Patients were examined clinically every half year. Minimum time of follow-up was two years. The last evaluation was a clinical examination at our outpatient clinic in the more recent cases or via mail in patients who underwent surgery more than five years ago. At first, the residual pain was assessed using VAS with the present-day score counted as a percentage decrease from the original level. Based on these scores, patients were divided into three groups according to intensity of residual pain (Table 2). Next the patients were assessed using the official Czech version of the painDETECT Questionnaire (PD-Q) [12]. This screening tool was chosen for its simplicity and because it does not require a clinical examination.

\section{Statistical analysis}

The results were analyzed using ANOVA with post-hoc analysis using the Fisher LSD test (for continuous data) 
Table 1 Group of patients undergoing DREZ thermocoagulation

\begin{tabular}{|c|c|c|c|c|c|c|}
\hline Patient & $\begin{array}{l}\text { Age (yrs), } \\
\text { Sex }\end{array}$ & $\begin{array}{l}\text { Number } \\
\text { of lesions }\end{array}$ & Complications & Effect & $\begin{array}{l}\text { PD-Q } \\
\text { score }\end{array}$ & $\begin{array}{l}\text { Follow- } \\
\text { up (mos) }\end{array}$ \\
\hline 1 & $27, \mathrm{~m}$ & 24 & - & 2 & 6 & 170 \\
\hline 2 & $45, f$ & 25 & - & 1 & 14 & 156 \\
\hline 3 & $28, m$ & 32 & - & 1 & 6 & 140 \\
\hline 4 & $45, m$ & 19 & - & - & - & D \\
\hline 5 & $51, m$ & 25 & - & 1 & 12 & 110 \\
\hline 6 & $25, m$ & 28 & - & 2 & 15 & 169 \\
\hline 7 & $23, m$ & 39 & Motor & 2 & 6 & 167 \\
\hline 8 & $47, m$ & 22 & - & - & - & $\mathrm{N} / \mathrm{A}$ \\
\hline 9 & $50, m$ & 15 & - & 3 & 33 & 155 \\
\hline 10 & $47, m$ & 29 & - & 1 & 6 & 178 \\
\hline 11 & $31, m$ & 45 & - & 2 & 15 & 150 \\
\hline 12 & $35, m$ & 25 & - & 1 & 4 & 139 \\
\hline 13 & $22, m$ & 25 & - & 1 & 10 & 180 \\
\hline 14 & $70, m$ & 31 & - & 1 & 6 & 120 \\
\hline 15 & $45, f$ & 21 & - & 2 & 18 & 113 \\
\hline 16 & $27, m$ & 33 & Motor & 2 & 7 & 115 \\
\hline 17 & $25, m$ & 29 & - & 1 & 8 & 159 \\
\hline 18 & $38, m$ & 42 & Sensory & 1 & 12 & 126 \\
\hline 19 & $40, m$ & 25 & - & 1 & 9 & 108 \\
\hline 20 & $48, m$ & 40 & - & 1 & 5 & 105 \\
\hline 21 & $40, m$ & 32 & - & 1 & 5 & 100 \\
\hline 22 & $39, m$ & 29 & - & - & - & $\mathrm{D}$ \\
\hline 23 & $50, m$ & 20 & - & - & - & $\mathrm{N} / \mathrm{A}$ \\
\hline 24 & $29, m$ & 47 & Sensory, Motor & 1 & 5 & 82 \\
\hline 25 & $40, m$ & 38 & - & 1 & 9 & 76 \\
\hline 26 & $58, m$ & 41 & - & 1 & 8 & 70 \\
\hline 27 & $35, m$ & 16 & - & 2 & 15 & 68 \\
\hline 28 & $55, m$ & 34 & - & 1 & 7 & 67 \\
\hline 29 & $38, m$ & 48 & - & 1 & 0 & 67 \\
\hline 30 & $31, \mathrm{~m}$ & 50 & - & 3 & 30 & 63 \\
\hline 31 & $35, m$ & 25 & - & 1 & 5 & 62 \\
\hline 32 & $51, m$ & 26 & - & 1 & 12 & 61 \\
\hline 33 & $24, m$ & 45 & - & 2 & 21 & 60 \\
\hline 34 & $47, m$ & 22 & Sensory & 1 & 9 & 59 \\
\hline 35 & $40, m$ & 18 & - & 1 & 10 & 58 \\
\hline 36 & $57, m$ & 29 & - & 1 & 5 & 57 \\
\hline 37 & $49, m$ & 20 & - & 3 & 24 & 51 \\
\hline 38 & $29, \mathrm{~m}$ & 37 & - & 1 & 16 & 50 \\
\hline 39 & $28, m$ & 26 & - & 1 & 13 & 49 \\
\hline 40 & $51, m$ & 44 & - & 1 & 17 & 48 \\
\hline 41 & $32, \mathrm{~m}$ & 25 & Sensory & 1 & 8 & 47 \\
\hline 42 & $45, m$ & 16 & - & 2 & 16 & 46 \\
\hline 43 & $28, m$ & 40 & - & 1 & 2 & 45 \\
\hline
\end{tabular}

Table 1 Group of patients undergoing DREZ thermocoagulation (Continued)

\begin{tabular}{|c|c|c|c|c|c|c|}
\hline 44 & $42, f$ & 37 & - & 1 & 5 & 44 \\
\hline 45 & $33, m$ & 29 & Sensory & 1 & 6 & 37 \\
\hline 46 & $33, \mathrm{~m}$ & 39 & - & 3 & 29 & 36 \\
\hline 47 & $41, m$ & 49 & Sensory & 2 & 25 & 33 \\
\hline 48 & $21, m$ & 39 & - & 1 & 4 & 32 \\
\hline 49 & $29, \mathrm{~m}$ & 28 & - & 1 & 4 & 31 \\
\hline 50 & $55, \mathrm{~m}$ & 25 & - & 1 & 14 & 28 \\
\hline 51 & $34, m$ & 33 & - & 1 & 5 & 26 \\
\hline 52 & $20, f$ & 34 & - & 1 & 6 & 26 \\
\hline
\end{tabular}

and Cramer's V and Yates Chi-square test (for categorical data). Analyses were done using Statistica 10.0 software (StatSoft Inc., Tulsa, Oklahoma, USA) and R (http://www. $\mathrm{r}$-project.org). Significance was assumed at $\mathrm{p}<0.05$.

\section{Results}

Thermal lesions were performed over the entire range of avulsions in all patients, the average number of lesions was $31(\mathrm{SD}=7.9$, range $15-50)$. Fifty-one patients had procedures before or just after reconstruction of the brachial plexus; one man was successfully treated 28 years after the original accident. Of the 441 patients undergoing a brachial plexus reconstruction, the thermal lesion group represented $11.8 \%$. Of 52 patients treated with thermal lesions, we were able to obtain data regarding the subjective assessment of their condition in 48 cases. Two men died of unrelated causes and another two patients could not be contacted for the final follow-up examination.

A decrease in pre-operative pain intensity of more than $75 \%$ was considered a definite success. Based on our follow-up, this goal was achieved in $70.8 \%$ of patients. Another 20.8\% reported significant improvement, but with some pain persistence, usually in the form of dull pain or paresthesias of the affected upper limb. Overall satisfaction with the surgery was achieved in $91.6 \%$ of patients. The surgery was considered to be unsuccessful in the remaining four cases (8.4\%). In two cases, after improvement in the early post-operative period, progressive worsening to the original level began at one and three months post-surgery. The two other cases reported persistence of very severe dull pain. In one case the patient decided to amputate the affected limb; however, this also failed to resolve the issue (No. 30).

The PD-Q score was in agreement with subjective assessments of residual pain: the average pain score in Group I (7.85) was statistically significantly lower than 
Table 2 Details of post-surgery residual pain

\begin{tabular}{lllll}
\hline & Decrease of preoperative pain & Number of patients (\%) & Average PD-Q score & Screening results No : Un : Ne (\%) \\
\hline Group I & $>75 \%$ & $34(70.8 \%)$ & $7.85(S D=3.25$, range 0-17)0* & $29(85.3 \% \#): 5(14.7 \%): 0$ \\
Group II & $75-50 \%$ & $10(20.8 \%)$ & $14.4(S D=4.8$, range 6-25)* & $3(30 \%): 5(50 \% \#): 2(20 \%)$ \\
Group III & $<50 \%$ & $4(8.4 \%)$ & $29(\mathrm{SD}=2.5$, range 24-33)* & $0: 0: 4(100 \% \#)$ \\
\hline
\end{tabular}

Decrease of preoperative pain - percentage decrease of preoperative VAS, PD-Q score - painDETECT Questionnaire score, Screening results: No - Nociceptive - a total score of $\leq 12$, a neuropathic pain component is unlikely, Un - result is unclear, a neuropathic pain component could be present, Ne - Neuropathic, a score of $\geq 19$, a neuropathic component is likely, Number of cases and (\%) - percentage of cases within main group. ${ }^{*}$ - statistically significant difference between all three groups ( $\mathrm{P}<.001$, ANOVA with post-hoc analysis using the Fisher LSD test), \# - statistically significant correlation between adequate groups (Group I No, Group II - Un, Group III - Ne) (Cramer's V = .66, Yates'Chi-square $\mathrm{P}<.001)$.

in Group II $(14.4, \mathrm{p}<0.001)$. Both are significantly lower than in Group III $(29, \mathrm{p}<0.001)$. We found a statistically significant correlation between adequate-treatment groups (Group I - Nociceptive pain, Group II - Unclear, Group III - Neuropathic pain) (Cramer's V 0.66, $\mathrm{p}<0.001)$. It was observed that $32 / 48(66.7 \%)$ patients lost neuropathic pain, 10/48 (20.8\%) patients had more serious complaints and may ultimately suffer from residual neuropathic pain while 6/48 (12.5\%) had neuropathic pain. Details are summarized in Table 2 and the values are shown in Figure 1.

Post-operative complications occurred in $8(15.4 \%)$ patients. In five cases, sensory deficits $(4 \times$ hypoesthesia of ipsilateral lower extremity, $1 \times$ hemihypoesthesia of the trunk and lower limb) occurred. Motor leg weakness occurred in two patients and one case had a combined disability. Excluding the patient with hemihypoesthesia, in which there was a partial restoration of body sensitivity, all other patient complaints resolved and returned to pre-operative conditions.

\section{Discussion}

The success and safety of DREZ-T in the treatment of intractable central pain caused by cervical root(s) avulsion have been confirmed repeatedly [2,6-10,13-15]. Generally, an immediate loss of pain can be achieved in 60 to $80 \%$ of cases, but the percentage decreases as time-after-accident increases. Some studies have found that the pain returns to some degree after several years in up to one-fifth of patients $[2,13,14]$; however, this was not confirmed by our study. Severe pain returned after several months only in two cases from Group III, none of the other patients reported any significant worsening or change of the quantity of residual pain over time. Some patients reported a change of quality of pain or irritations, but the change did not have a significant impact on their opinion regarding the effectiveness of the surgery.

An operative painkilling surgery is generally required in 10 to $15 \%$ of patients with spinal cord root avulsion $[16,17]$. Chen et al., for example, found that in a group of more than 500 patients, 60 DREZ thermocoagulations were performed ( 12\%) [13]. Our set of $11.8 \%$ corresponds to foreign experiences $[13,18]$.

We divided patients into three groups (Table 2) according to Aichaoui et al.: Group I corresponds to VAS reduction up to $75 \%$, these patients do not require supplemental analgesics, Group II - VAS reduction was between 50 and $75 \%$, patients sometimes take analgesics and retrospectively would still agree to have the surgery, and Group III, which corresponds to VAS decrease less than $50 \%$, such patients usually take painkillers (WHO Class II or opioids) and retrospectively would not undergo the surgery again.

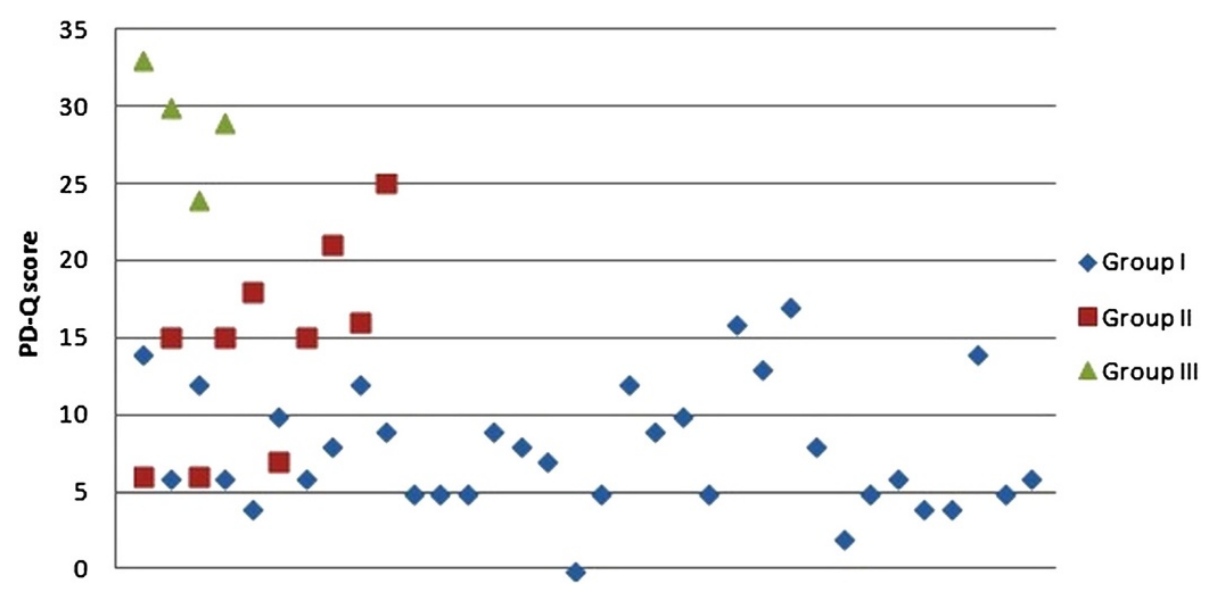

Figure 1 PainDETECT Questionnaire score (PD-Q score) in all three groups. For details see Table 2. 
It has been stated that there is no correlation between the number of roots avulsed or the extent of the DREZ$\mathrm{T}$ procedure performed and the degree of pain reduction [17]. The best results have been achieved in sporadic irritations while persistent dull pain had a worse prognosis and higher tendency to recur $[1,19]$. This is in accordance with our study - all 10 patients from Group II had residual dull pain and only two from Group III had the same pain as before the surgery, while another two were relieved of only the strongest paroxysmal irritations. The results show that paroxysmal pain was successfully eliminated in $91.6 \%$ while severe dull pain was treatable in $70.8 \%$ cases. Patients from Group I usually reported only paroxysmal paresthesias or mild paroxysmal dull pain; some of them realized, for the first time during testing, that they still had some sensory disturbances. Our results are also parallel those presented in the broader literature $[1,2,13,14]$.

The PD-Q was validated in a group of 392 individuals with nociceptive and neuropathic pain. Of its nine items, seven relate to sensory responses and two relate to temporal and spatial characteristics of the pain pattern. A total score $\leq 12$ indicates that a neuropathic pain component is unlikely, whereas a score of $\geq 19$ indicates that a neuropathic component is likely. Between these values the result are uncertain and a neuropathic pain component could be present. It has more than $80 \%$ sensitivity, specificity and positive predictive accuracy in the diagnosis of a neuropathic component in patients with low back pain [12]. This scale was used for evaluation of neuropathic pain in patients with spinal cord injuries with $68 \%$ sensitivity, $83 \%$ specificity and $78 \%$ diagnostic accuracy [20]. It can be also used for other types of neuropathic pain [21]. We used this screening tool because many of our patients live far from our department and were not inclined to travel to our facility for a clinical assessment so many years after surgery.

If we compare the success rate using a VAS decrease and the PD-Q scale, the results are similar $(\mathrm{p}<0.001)$ : $70.8 \%$ (Group I): $66.7 \%$ (nociceptive pain), $20.8 \%$ (Group II): $20.8 \%$ (unclear pain) and $8.4 \%$ (Group III): $12.5 \%$ (neuropathic pain). The small differences probably result from (1) individual subjective assessment of pain intensity or (2) even if pre-operative pain intensity decreased dramatically, it is still possible that the patient has residual neuropathic pain. Our results suggest two clear conclusions about residual pain in our patients: (1) patients who are very satisfied with the effect of surgery (Group I) most often suffered from (obvious) nociceptive pain $(85.3 \%)$ and (2) patients, in whom the surgery failed, had suffered from (obvious) neuropathic pain (100\%, $\mathrm{p}<0.001)$. Patients in Group II, who were partially satisfied with the effectiveness of the surgery, might very well, suffer from a combination of nociceptive and neuropathic pain. The presence of nociceptive pain after brachial plexus injury seems to be unexpected. However, it may originate in the areas of preserved nerve supply in incomplete injuries or develop later in the areas reinnervated by neurotization. We can therefore conclude that it would be useful to evaluate patients who were not fully satisfied with the effectiveness of the DREZ-T surgery, using a screening tool like the PD-Q, which could reveal a potential neuropathic component of their residual pain. In such cases, a more effective conservative treatment would be indicated.

The risk of this procedure includes potentially serious neurological complications. The close proximity of corticospinal tract laterally and dorsal column medial lemniscal tract dorso-medially creates a risk motor failure of the ipsilateral lower extremity or sensitivity failure from the point of damage with lower limb ataxia, respectively. Anatomical and functional localization of DREZ is therefore essential for overall success. With careful monitoring, finding of vertical zero line is not usually difficult even though it is known that the distance from the midline to the DREZ can be quite variable [22]. Problems tend to occur in cases involving multiple avulsions with the presence of pseudomeningocele and dural scarring. They can cause changes in spinal anatomical arrangement of the surface. Needless to say, such delicate procedures require masterful execution; additionally, the radiofrequency electrode must be inserted to maximum depth of $2 \mathrm{~mm}$ and must be completely perpendicularly to the surface of the spinal cord and must be used in compliance with prescribed parameters $\left(75^{\circ} \mathrm{C}, 15\right.$ seconds $)[6,7,10]$. The incidence of complications is different for different authors, ranging from 0 to $60 \%$ [18]. In our group, the frequency of complications was $15.4 \%$.

Recent information has clouded the issue of deafferentation pain and made it a little less simple than previously thought. Deafferentation pain probably does not occur in children (both older with traumatic injuries, and infants with perinatal injuries) [23]. Aly et al. reported that electrical motor cortex stimulation is more effective for continuous than paroxysmal pain after brachial plexus injury [24]. The complete disappearance of pain after successful reinnervation [22] or only after endoneurolysis or neuroma removal [25] has been described. According to Bertelli et al., not all pain should be considered as deafferentation pain. They observed that in 400 patients, following rhizotomy performed for spasticity, deafferentation pain did not develop [3]. Other work from Bertelli suggests that the pain is not caused (or at least not always) by the avulsion, but is generated by the root(s), which remained intact. In $80 \%$ of patients with at least one well-preserved root, the pain subsided within three weeks after grafting. Another group, pain from an old injury was eliminated after selective anesthesia of preserved root using a CT-navigated technique [26]. The most recent study published by this author shows that pain 
occurs most frequently in complete brachial plexus palsy (84\%) and, more interestingly, in cases where the avulsion of C8-Th1 was the only injury, deafferentation pain was never present [27]. Bonilla et al. described similar results with the subsidence of irritations after plexus element neurolysis or reconstruction, with pain subsiding in $78 \%$ of cases [6]. These studies are, however, not confirmed by published DREZ-T results $[8,14]$ or by the case report of a man who was still pain free 26 years after the procedure [28] or by our current results. We think DREZ thermocoagulation is still a very effective method for treatment of severe neuropathic pain that can develops in some patients with supra-ganglion brachial plexus injury.

\section{Conclusion}

We conclude that approximately $90 \%$ of our patients were satisfied with the effectiveness of DREZ thermocoagulation for intractable deafferentation pain after a brachial plexus injury.

\section{Competing interests}

The authors declare that they have no competing interests.

\section{Authors' contributions}

$\mathrm{PH}$ conceived and coordinated the study. RK designed the study, participated in acquisition and analysis of the presented data and wrote the manuscript. LM participated in acquisition of the presented data. PW participated in analysis of the presented data. All authors gave final approval of the version to be published.

\section{Acknowledgements}

This study was supported by Charles University in Prague, PRVOUK P34.

\section{Author details}

${ }^{1}$ Department of Neurosurgery, Third Faculty of Medicine, Charles University, Hospital Kralovske Vinohrady, Srobarova 50100 34, Prague, Czech Republic. ${ }^{2}$ Department of Anesthesiology and Critical Care Medicine, Third Faculty of Medicine, Charles University, Hospital Kralovske Vinohrady, Prague, Czech Republic.

Received: 9 July 2013 Accepted: 12 November 2014

Published online: 09 December 2014

\section{References}

1. Aichaoui F, Mertens $P$, Sindou M: Dorsal root entry zone lesioning for pain after brachial plexus avulsion: Results with special emphasis on differential effects on the paroxysmal versus the continuous components. A prospective study in a 29-patient consecutive series. Pain 2011, 152(8):1923-1930.

2. Sindou MP, Blondet E, Emery E, Mertens P: Microsurgical lesioning in the dorsal root entry zone for pain due to brachial plexus avulsion: $A$ prospective series of 55 patients. J Neurosurg 2005, 102(6):1018-1028.

3. Bertelli JA, Ghizoni MF: Concepts of nerve regeneration and repair applied to brachial plexus reconstruction. Microsurgery 2006, 26(4):230-244.

4. Ambler Z, Bednarík J, Keller O: Recommended method of treatment of neuropathic pain. Cesk Slov Neurol N 2002, 65(3):135-138.

5. Attal N, Cruccu G, Baron R, Haanpää M, Hansson P, Jensen TS, Nurmikko T: EFNS guidelines on the pharmacological treatment of neuropathic pain: 2009 revision. Eur J Neurol 2010, 17:1113-e88.

6. Bonilla G, Di Masi G, Battaglia D, Otero JM, Socolovsky M: Pain and brachial plexus lesions: evaluation of initial outcomes after reconstructive microsurgery and validation of a new pain severity scale. Acta Neurochir (Wien) 2011, 153(1):171-176.

7. Haninec $P$, Tomáš $R$, Sereghy $T$, Houštava L: Drez thermocoagulation in treatment of deafferentation pain. Bolest 2002, 5(3):177-180.
8. Nashold BS, Ostdahl RH: Dorsal root entry zone lesions for pain relief. J Neurosurg 1979, 51:59-69.

9. Sindou M: Microsurgical DREZotomy (MDT) for pain, spasticity, and hyperactive bladder: A 20-year experience. Acta Neurochir 1995, 137(1-2):1-5.

10. Tomáš $R$, Haninec $P$ : Dorsal root entry zone (DREZ) localization using direct spinal cord stimulation can improve results of the DREZ termocoagulation procedure for intractable pain relief. Pain 2005, 116:159-163.

11. Spaić M, Ivanović S, Slavik E, Antić B: DREZ (dorsal root entry zone) surgery for the treatment of the postherpetic intercostal neuralgia. Acta Chir lugos/ 2004, 51(4):53-57.

12. Freynhagen $R$, Baron $R$, Gockel U, Tölle TR: painDETECT: A new screening questionnaire to identify neuropathic components in patients with back pain. Curr Med Res Opin 2006, 22(10):1911-1920.

13. Chen HJ, Tu YK: Long term follow-up results of dorsal root entry zone lesions for intractable pain after brachial plexus avulsion injuries. Acta Neurochir Suppl 2006, 99:73-75.

14. Ruiz-Juretschke F, García-Salazar F, García-Leal R, Fernández-Carballal C, Iza B, Garbizu JM, García-Duque S, Panadero T: Treatment of neuropathic deafferentation pain using DREZ lesions; long-term results. Neurologia 2011, 26(1):26-31.

15. Zheng Z, Hu Y, Tao W, Zhang X, Li Y: Dorsal root entry zone lesions for phantom limb pain with brachial plexus avulsion: A study of pain and phantom limb sensation. Stereotact Funct Neurosurg 2009, 87(4):249-255.

16. Campbell JN, Solomon CT, James CS: The Hopkins experience with lesions of the dorsal horn (Nashold's operation) for pain from avulsion of the brachial plexus. App/ Neurophysiol 1988, 51:170-174.

17. Samii M, Bear-Henney S, Ludemann W, Tatagiba M, Blomer U: Treatment of Refractory Pain after Brachial Plexus Avulsion with Dorsal Root Entry Zone Lesions. Neurosurgery 2001, 48:1269-1275.

18. Fazl M, Houlden DA, Kiss Z: Spinal cord mapping with evoked responses for accurate localization of the dorsal root entry zone. J Neurosurg 1995, 82:587-591.

19. Aly MM, Saitoh Y, Kishima H, Hosomi K, Yoshimine T: Importance of distinction between paroxysmal and continuous patterns of pain during evaluation of pain after brachial plexus injury. Acta Neurochir (Wien) 2011, 153(2):437-438.

20. Hallström H, Norrbrink C: Screening tools for neuropathic pain: Can they be of use in individuals with spinal cord injury? Pain 2011, 152(4):772-779.

21. Haroutiunian S, Nikolajsen L, Finnerup NB, Jensen TS: The neuropathic component in persistent postsurgical pain: A systematic literature review. Pain 2013, 154(1):95-102.

22. Karatas A, Caglar S, Savas A, Elhan A, Erdogan A: Microsurgical anatomy of the dorsal cervical rootlets and dorsal root entry zones. Acta Neurochir 2005, 147(2):195-199.

23. Gilbert A, Pivato $G$, Kheiralla $T$ : Long-term results of primary repair of brachial plexus lesions in children. Microsurgery 2006, 26(4):334-342.

24. Ali M, Saitoh Y, Oshino S, Hosomi K, Kishima H, Morris S, Shibata M, Yoshimine T: Differential efficacy of electric motor cortex stimulation and lesioning of the dorsal root entry zone for continuous vs paroxysmal pain after brachial plexus avulsion. Neurosurgery 2011, 68(5):1252-1257.

25. Carlstedt T, Anand P, Htut M, Misra P, Svensson M: Restoration of hand function and so called "breathing arm" after intraspinal repair of C5-T1 brachial plexus avulsion injury, Case report. Neurosurg Focus 2004, 16(5):E7.

26. Bertelli JA, Ghizoni MF: Pain after avulsion injuries and complete palsy of the brachial plexus: the possible role of nonavulsed roots in pain generation. Neurosurgery 2008, 62(5):1104-1113.

27. Bertelli JA, Ghizoni MF, Loure Iro Chaves DP: Sensory disturbances and pain complaints after brachial plexus root injury: A prospective study involving 150 adult patients. Microsurgery 2011, 31(2):93-97.

28. Tomycz ND, Moossy JJ: Follow-up 26 years after dorsal root entry zone thermocoagulation for brachial plexus avulsion and phantom limb pain. J Neurosurg 2011, 114(1):196-199.

\section{doi:10.1186/s12883-014-0225-9}

Cite this article as: Haninec et al:: Usefulness of screening tools in the evaluation of long-term effectiveness of DREZ lesioning in the treatment of neuropathic pain after brachial plexus injury. BMC Neurology 2014 14:225. 